\title{
AGS-3 Alters Caenorhabditis elegans Behavior after Food Deprivation via RIC-8 Activation of the Neural G Protein $\mathrm{G} \alpha_{\mathrm{o}}$
}

\author{
Catherine Hofler and Michael R. Koelle \\ Department of Molecular Biophysics and Biochemistry, Yale University, New Haven, Connecticut 06520-8024
}

Proteins containing the $\mathrm{G}$ protein regulator (GPR) domain bind the major neural $\mathrm{G}$ protein $\mathrm{G} \alpha_{\mathrm{o}}$ in vitro. However, the biological functions of GPR proteins in neurons remain undefined, and based on the in vitro activities of GPR proteins it is unclear whether these proteins activate or inhibit $\mathrm{G}$ protein signaling in vivo. We found that the conserved GPR domain protein AGS-3 activates $\mathrm{G} \alpha_{\mathrm{o}}$ signaling in vivo to allow Caenorhabditis elegans to alter several behaviors after food deprivation, apparently so that the animals can more effectively seek food. AGS-3 undergoes a progressive change in its biochemical fractionation upon food deprivation, suggesting that effects of food deprivation are mediated by modifying this protein. We analyzed one C. elegans food-regulated behavior in depth; AGS-3 activates $\mathrm{G} \alpha_{\mathrm{o}}$ in the ASH chemosensory neurons to allow food-deprived animals to delay response to the aversive stimulus octanol. Genetic epistasis experiments show the following: (1) AGS-3 and the guanine nucleotide exchange factor RIC-8 act in ASH in a mutually dependent fashion to activate $\mathrm{G} \alpha_{0}$; (2) this activation requires interaction of the GPR domains of AGS-3 with $\mathrm{G} \alpha_{0}$; and (3) G $\alpha_{0}$-GTP is ultimately the signaling molecule that acts in ASH to delay octanol response. These results identify a biological role for AGS-3 in response to food deprivation and indicate the mechanism for its activation of $\mathrm{G} \alpha_{\mathrm{o}}$ signaling in vivo.

\section{Introduction}

Behavioral responses to food deprivation are a fundamental aspect of nervous system function in all animals and thus could have a conserved underlying mechanism amenable to study in simple model organisms. Signaling molecules that act on the nervous system to alter behaviors in response to hunger are conserved from Caenorhabditis elegans to humans (Gruninger et al., 2007). Upon food deprivation in mammals, signaling from the periphery affects release of hypothalamic peptides such as neuropeptide $\mathrm{Y}$ and ultimately controls dopamine release in several brain regions to alter feeding and metabolism (Vucetic and Reyes, 2010; Pandit et al., 2011). In C. elegans, dopamine release is also controlled by exposure to food and acts to alter behaviors after food deprivation (Hills et al., 2004; Ezak and Ferkey, 2010). In one such evolutionarily adaptive response, well fed C. elegans back away quickly from dilute octanol, but food-deprived C. elegans continue to move toward this aversive stimulus and can thus access food near it. Dopamine and several of the peptides that affect feeding can all signal through the abundant neural $G$

\footnotetext{
Received April 24, 2011; revised May 27, 2011; accepted June 14, 2011.

Author contributions: C.H. and M.R.K. designed research; C.H. conducted research; C.H. and M.R.K. wrote the paper.

This work was supported by National Institutes of Health Grant NS36918 (to M.R.K.) and a National Science Foundation predoctoral fellowship (to C.H.).We thank the Caenorhabditis Genetics (enter and the Japanese National BioResource Project for strains. We thank Denise Ferkey (University of Buffalo) for help with the octanol assays. The authors declare no competing financial interests.

Correspondence should be addressed to Michael R. Koelle, 333 Cedar Street, SHM CE-30, New Haven, CT 065208024. E-mail: michael.koelle@yale.edu.

DOI:10.1523/JNEUROSCI.2072-11.2011

Copyright $\odot 2011$ the authors $\quad 0270-6474 / 11 / 3111553-10 \$ 15.00 / 0$
}

protein $\mathrm{G} \alpha_{\mathrm{o}}$. Thus, it is necessary to understand the mechanisms that regulate $\mathrm{G} \alpha_{\mathrm{o}}$ signaling to understand the regulation of behaviors by food deprivation.

$\mathrm{G} \alpha_{\mathrm{o}}$ has been shown by yeast two-hybrid and functional screens to bind proteins containing the $\sim 25$ amino acid $G$ protein regulator (GPR) domain, also called the GoLoco domain (Mochizuki et al., 1996; Kimple et al., 2002). In vitro, GPR domains bind to the inactive GDP-bound state of $\mathrm{G} \alpha_{\mathrm{i} / \mathrm{o}}$, inhibit nucleotide exchange by $\mathrm{G} \alpha$, and compete with the $\mathrm{G} \beta \gamma$ dimer for G $\alpha$ binding (Takesono et al., 1999; Natochin et al., 2000; Bernard et al., 2001; Kopein and Katanaev, 2009). Additional biochemical studies have shown that the guanine nucleotide exchange factor Ric- 8 A can activate $\mathrm{G} \alpha$ by promoting exchange of GDP for GTP when $\mathrm{G} \alpha$ is bound to a GPR domain (Tall and Gilman, 2005; Thomas et al., 2008), but not when $\mathrm{G} \alpha$ is bound to $\mathrm{G} \beta \gamma$ (Tall et al., 2003). From these in vitro studies it is unclear whether GPR domain-containing proteins inhibit $\mathrm{G}$ protein signaling by preventing nucleotide exchange on $\mathrm{G} \alpha$, or whether they promote $\mathrm{G}$ protein signaling by sequestering $\mathrm{G} \alpha$ from $\mathrm{G} \beta \gamma$ so that free $\mathrm{G} \beta \gamma$ can signal and $\mathrm{G} \alpha$ can remain in a form that can be activated by Ric-8A.

In vivo studies of GPR domain proteins have focused on their role in regulating mitotic spindle positioning during asymmetric cell division (Miller and Rand, 2000; Schaefer et al., 2000; Du et al., 2001; Gotta et al., 2003; Srinivasan et al., 2003; David et al., 2005; Hampoelz et al., 2005; Sanada and Tsai, 2005; Wang et al., 2005), but the functional relationships between the $G$ proteins and GPR domain proteins in cell division remain undefined. In addition, GPR domain proteins are expressed in adult neurons that do not divide (Bernard et al., 2001; Blumer et al., 2002), 
suggesting they have roles beyond controlling cell division. Whether and how GPR proteins affect G protein signaling in adult neurons remains unclear.

\section{Materials and Methods}

\section{Protein expression and purification}

A full-length ags-3 cDNA was generated by reverse transcription PCR. RNA was extracted from mixed-stage wild-type animals using TRIzol reagent (Invitrogen). Briefly, $100 \mu$ l of packed worms were vortexed with four volumes of TRIzol, frozen in liquid nitrogen, and thawed at $37^{\circ} \mathrm{C}$, and this process was repeated. Two volumes of chloroform were added and the solution was mixed for $15 \mathrm{~s}$ before centrifuging at $1000 \times g$ for 15 $\min$ at $4^{\circ} \mathrm{C}$. The clear supernatant was transferred to a fresh tube, and RNA was precipitated in an equal volume isopropanol for $10 \mathrm{~min}$ at room temperature, washed in $0.5 \mathrm{ml}$ of $70 \%$ ethanol, resuspended in 100 $\mu l$ of DEPC-treated water, and stored at $-80^{\circ} \mathrm{C}$. ags- 3 first-strand cDNA was transcribed from the RNA using Moloney murine leukemia virus reverse transcriptase (Roche) and gene-specific primers (Integrated DNA Technologies). PCR was performed using Phusion high-fidelity polymerase (New England Biolabs). Amplicons were purified by gel extraction with QiaQuick spin columns (Qiagen) and sequenced by the Keck facility at Yale. The ags-3 cDNA was cloned into the NotI and KpnI restriction sites of the protein expression vector pMD49 (Dong et al., 2000), which adds GST, 6His, and a tobacco etch virus (TEV) cleavage site to the $\mathrm{N}$ terminus of the protein.

AGS-3 protein was expressed in BL21 DE3 Escherichia coli cells grown overnight in LB broth at $18^{\circ} \mathrm{C}$. The bacterial pellet was lysed in lysis buffer (50 mm HEPES, pH 7.2, 1 mm EDTA, 150 mM NaCl, 10\% glycerol, 1 mm DTT, $1 \mathrm{~mm}$ PMSF, $1 \mu \mathrm{g} / \mu \mathrm{l}$ each leupeptin and pepstatin) using a French press at 15,000 psi, and the soluble fraction was separated from insoluble components by a $100,000 \times g$ spin at $4^{\circ} \mathrm{C}$ in a Ti70.1 rotor and Beckman ultracentrifuge. The GST-6His-TEV-AGS-3 protein was batch purified using glutathione Sepharose 4B beads (GE Healthcare). The bound protein was washed in lysis buffer with $11 \mathrm{~mm} \mathrm{Mg}^{2+}$ and $2 \mathrm{~mm}$ ATP before batch elution with $10 \mathrm{~mm}$ glutathione. The glutathione was removed and the buffer exchanged to HED buffer [containing (in mM): 50 HEPES, $\mathrm{pH}$ 8.0, 1 EDTA, and 1 DTT] by running the eluted protein over a PD-10 desalting column (GE Healthcare). Peak fractions (as determined by Bradford assay) were combined for a final protein yield of $10 \mathrm{mg} / \mathrm{L}$ of bacterial culture. GST-6His-TEV-GPR (yield $=1.0 \mathrm{mg} / \mathrm{L}$ ) was similarly purified. C. elegans $\mathrm{G} \alpha_{\mathrm{o}}$ (yield $=1.6 \mathrm{mg} / \mathrm{L}$ ) was purified as described previously (Dong et al., 2000). Protein aliquots were flash frozen in liquid nitrogen and stored at $-80^{\circ} \mathrm{C}$.

\section{Protein binding assays}

$\mathrm{G} \alpha_{\mathrm{o}}(8 \mu \mathrm{M})$ was preincubated for $1 \mathrm{~h}$ at room temperature with either 10 $\mu \mathrm{M}$ GDP, $10 \mu \mathrm{M}$ GDP with $20 \mu \mathrm{M} \mathrm{AlCl}$ and $10 \mathrm{~mm} \mathrm{NaF}$, or $10 \mu \mathrm{M} \mathrm{GTP} \gamma \mathrm{S}$ in binding buffer [containing (in mM): 50 HEPES, pH 8.0, 1 EDTA, 10 $\left.\mathrm{MgSO}_{4}, 1 \mathrm{DTT}\right]$. One hundred twenty microliters of $8 \mu \mathrm{M}$ GST-AGS-3, GST-GPR, or GST were bound to $30 \mu \mathrm{l}$ GE Healthcare glutathione Sepharose $4 \mathrm{~B}$ beads in binding buffer in $1.5 \mathrm{ml}$ microcentrifuge tubes (USA Scientific) by rotating for $1 \mathrm{~h}$ at room temperature. The beads with bound protein were divided equally into three $0.2 \mathrm{ml}$ thin wall tubes (USA Scientific) and spun for $30 \mathrm{~s}$ at $16,100 \times g$ in a tabletop microcentrifuge to remove the supernatant. Forty microliters of $6 \mu \mathrm{M} \mathrm{G} \alpha_{\mathrm{o}}$ preincubated in each of the three nucleotide conditions was added to the GST fusion proteins on Sepharose beads and incubated at room temperature with rotating. After $1 \mathrm{~h}$, beads were spun down at $16,100 \times g$ and the supernatant was removed to a new $1.5 \mathrm{ml}$ microcentrifuge tube using a Hamilton syringe. The beads were washed twice with $200 \mu$ l binding buffer and the appropriate nucleotide. Ten microliters of $5 \times$ sample buffer (250 mm Tris, pH 6.8, 5\% SDS, 37.5\% glycerol, $10 \mathrm{~m}$ urea, bromophenol blue) was added to each supernatant sample, and $50 \mu \mathrm{l}$ of $5 \times$ sample buffer was added to each bead pellet sample. All samples were boiled for $5 \mathrm{~min}$ before $35 \mu \mathrm{l}$ of each sample was run on 10\% SDS-PAGE, and the gels were Coomassie stained.

\section{C. elegans strains}

C. elegans strains were cultured at $20^{\circ} \mathrm{C}$ on nematode growth medium (NGM) agar plates with E. coli strain OP50 as a food source (Brenner,
1974). All ags-3 gene deletion strains were outcrossed four times to the wild-type strain. The wild-type strain was Bristol N2. All additional $C$. elegans strains used in this work were as follows:

Figure 2: LX1633 lin-15(n765) X; vsEx668.

Figure 3: N2, LX1573 ags-3( gk517) X, LX1575 ags-3(tm2342) X, LX1574 ags-3(vs104) X, LX1535 ags-3(ok1169) X, LX1576 ags-3(tm2375) X, MT2426 goa-1(n1134) I, JT734 goa-1(sa734) I.

Figure 4: N2, CB1112 cat-2(e1112) II, LX1573 ags-3( gk517) X, LX1575 ags-3(tm2342) X, MT2426 goa-1(n1134) I, LX1655 goa1(n1134) I; ags-3( gk517) X, LX850 lin-15(n765) X; vsIs50.

Figure 5: N2.

Figure 6: LX1633 lin-15(n765) X; vsEx668, LX1767 lin-15(n765) X; vsEx703, LX1752 lin-15(n765) X; vsEx697, LX1753 ags-3( gk517) lin15(n765) X; vsEx697, LX1761 goa-1(n1134) I; lin-15(n765) X; vsEx697, LX1749 lin-15(n765) X; vsEx698, LX1757 ags-3( gk517) lin-15(n765) X; vsEx698, LX1762 goa-1(n1134) I; lin-15(n765) X; vsEx698, LX1759 ags3( gk517) lin-15(n765) X; vsEx687, LX1751 lin-15(n765) X; vsEx700, LX1764 goa-1(n1134) I; lin-15(n765) X; vsEx701, LX1750 lin-15(n765) X; vsEx699, LX1758 ags-3(gk517) lin-15(n765) X; vsEx699, LX1763 goa-1(n1134) I; lin-15(n765) X; vsEx699, LX1765 goa-1(n1134) I; lin15(n765) X; vsEx702, LX1741 lin-15(n765) X; vsEx688, LX1742 ags3( gk517) lin-15 (n765) X; vsEx688, LX1743 goa-1 (n1134) I; lin-15(n765) X; vsEx688, LX1744 lin-15(n765) X; vsEx689, LX1745 lin-15(n765) X; vsEx690, LX1746 lin-15(n765) X; vsEx691, LX1747 lin-15(n765) X; vsEx692, LX1748 lin-15(n765) X; vsEx693.

\section{Transgenes}

Transgenic strains were constructed by injection of plasmid DNA into the germline.

\section{Analysis of sequence similarity between AGS3 family members}

The dendrogram of C. elegans GPR-1, GPR-2, and AGS-3, Drosophila Pins, and human LGN and AGS3 proteins was created using the MegAlign program (DNAStAR Lasergene). The ClustalW method was used to align the protein sequences.

\section{Microscopy}

Animals were immobilized for microscopy on agar pads with a drop of $20 \mathrm{~mm}$ muscimol in M9 buffer. Animals containing ags-3::GFP reporter transgenes were imaged with a Zeiss LSM 510 confocal microscope and reconstructed using Volocity software (Improvision). For images of eggs retained in utero, animals were photographed using a Carl Zeiss Axioskop.

\section{AGS-3 antibody}

AGS-3 antisera were raised in rabbits against full-length GST-AGS-3 by Cocalico Biologicals. Antisera collected after the fourth immunization were affinity purified against a maltose binding protein-AGS-3 fusion (purification yield $=0.9 \mathrm{mg} / \mathrm{L}$ ), immobilized on SulfoLink coupling resin (Thermo Scientific, catalog no. 20401) in a $5 \mathrm{ml}$ disposable column (Pierce, catalog no. 29925), and eluted in $100 \mathrm{~mm}$ glycine, pH 2.2. After neutralizing with 0.1 volume of $1 \mathrm{M}$ Tris- $\mathrm{Cl}, \mathrm{pH} 8$, and adding BSA to $1 \mathrm{mg} / \mathrm{ml}$, antisera aliquots were flash frozen in liquid nitrogen and stored at $-80^{\circ} \mathrm{C}$.

\section{C. elegans behavioral assays}

All animals were grown and assayed at $20^{\circ} \mathrm{C}$ on NGM agar plates. Staged adult hermaphrodites were produced by picking animals at the late fourth larval stage (L4) based on the morphology of the differentiating vulva and aging them for a specific number of hours before assay.

Steady-state egg laying. The unlaid eggs accumulated in well fed adult animals ( $40 \mathrm{~h}$ post-L4), an indirect measure of their egg-laying behavior, were counted as described by Chase and Koelle (2004).

Egg laying during food deprivation. Animals were assayed at $40 \mathrm{~h}$ postL4. Staged worms were picked to an unseeded plate and allowed to crawl away from any residual food for 1-5 min. Ten animals were then picked to a new unseeded plate (food-deprived condition) or a plated seeded with OP50 bacteria (fed condition). Each plate had a ring of $4 \mathrm{~m}$ fructose in water, applied 10-20 min before the assay, around the outer edge to act 
as an osmotic barrier. After $1 \mathrm{~h}$, the adults were removed from the plate and the number of laid eggs was counted.

Area-restricted search. Animals were assayed at $24 \mathrm{~h}$ post-L4 as described by Hills et al. (2004). Individual animals were picked to an unseeded plate and allowed to crawl away from their starting point for $10 \mathrm{~s}$. The animal was then picked to a new unseeded plate and allowed to crawl for a total of $35 \mathrm{~min}$. The number of high-angle turns executed by each animal was counted during the first $5 \mathrm{~min}$ and the last $5 \mathrm{~min}$. High-angle turns, also called $\Omega$ turns, consisted of backing, followed by the animal turning and touching the tip of its nose to its tail and then moving forward in the direction opposite to the direction of its initial forward movement.

Avoidance of dilute octanol. Animals were assayed at $24 \mathrm{~h}$ post-L4 as described by Chao et al. (2004). A fresh $100 \mu$ l stock of $30 \%$ octanol in $100 \%$ ethanol was made up each day the assay was performed. Animals were picked to an unseeded plate and allowed to crawl away from their starting point for at least $10 \mathrm{~s}$. Three animals were then picked to a freshly poured (poured within $24 \mathrm{~h}$ ) unseeded (food-deprived condition) or OP50-seeded (fed condition) plate and incubated at $22-24^{\circ} \mathrm{C}$ for $12-20$ min. Individual animals were assayed by placing a sable brush hair (Jack Richeson Pure Kolinsky Sable 1 Flat Watercolor Brush; Amazon Standard Identification Number: B0009I865E) dipped in 30\% octanol in front of a forward moving worm. The time to the first reversal following stimulus presentation was counted using a metronome set to beat at 1 $\mathrm{Hz}$. If no reversal occurred within $20 \mathrm{~s}$, the animal was discarded from the assay. Each day the assay was performed, wild-type control animals were assayed to ensure that the plates contained the level of moisture required for the assay to give proper results. In general, the moisture level of the plate must be such that the animals left no or very light tracks in the agar when moving, but there was no visible meniscus of liquid around the animals. If the wild-type control animals did not reverse in response to dilute octanol within 2-4 s on food and within 8-10 s after food deprivation on a given assay day, the entire day's assay was discontinued and the data discarded.

Small-scale liquid culture of C. elegans

Small-scale liquid culture of $C$. elegans was performed as described by Porter and Koelle (2010). Concentrated E. coli HB101 was prepared by growing it in 2 liters of $\mathrm{LB}$ broth overnight at $37^{\circ} \mathrm{C}$ with shaking at 200 $\mathrm{rpm}$. The bacteria were spun down for $15 \mathrm{~min}$ at $1500 \times g$ at $4^{\circ} \mathrm{C}$ and resuspended in $25 \mathrm{ml}$ of S-basal buffer $\left(100 \mathrm{~mm} \mathrm{NaCl}, 50 \mathrm{~mm} \mathrm{K \textrm {K } _ { 2 }} \mathrm{PO}_{4}\right.$, $\mathrm{pH} 6.0,5 \mu \mathrm{g} / \mathrm{ml}$ cholesterol) by vortexing. Concentrated HB101 was stored in $50 \mathrm{ml}$ polypropylene Falcon tubes at $4^{\circ} \mathrm{C}$ for up to 2 weeks.

For growth in liquid culture, C. elegans animals from an almoststarved $5 \mathrm{~cm}$ NGM plate were washed into $15 \mathrm{ml} \mathrm{S}$-basal buffer $(100 \mathrm{mM}$ $\mathrm{NaCl}, 50 \mathrm{~mm} \mathrm{KH}_{2} \mathrm{PO}_{4}$, pH 6.0, $5 \mu \mathrm{g} / \mathrm{ml}$ cholesterol) supplemented with

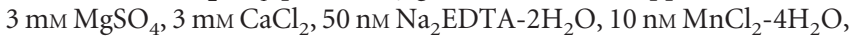
$25 \mathrm{~nm} \mathrm{FeSO}_{4}-7 \mathrm{H}_{2} \mathrm{O}, 10 \mathrm{~nm} \mathrm{ZnSO}-7 \mathrm{H}_{2} \mathrm{O}, 1 \mathrm{~nm} \mathrm{CuSO}{ }_{4}-5 \mathrm{H}_{2} \mathrm{O}, 10 \mathrm{~mm}$ potassium citrate, $\mathrm{pH}$ 6.0, penicillin/streptomycin (Invitrogen), and Nystatin (Sigma) in a $125 \mathrm{ml}$ glass Erlenmeyer flask. Five milliliters of concentrated HB101 bacteria was added to each flask as food, and the cultures were grown for $3-4 \mathrm{~d}$ at $20^{\circ} \mathrm{C}$ with shaking at $180 \mathrm{rpm}$ until a 20 $\mu l$ drop of the culture dropped onto an unseeded NGM plate contained hundreds of worms. To ensure that the culture was well fed, we checked that this $20 \mu \mathrm{l}$ drop left a thin lawn of HB101 bacteria on the plate after the agar absorbed the liquid.

The cultures were prepped by pouring the culture into $15 \mathrm{ml}$ polypropylene Falcon tubes and spinning at $1500 \times g$ for $2 \mathrm{~min}$ in a swinging bucket centrifuge at room temperature. The resulting pellet was washed twice by resuspension in $15 \mathrm{ml} 0.1 \mathrm{M} \mathrm{NaCl}$ and spinning down as before. The remaining HB101 bacteria was removed from the C. elegans culture by bringing the volume of the pellet up to $5 \mathrm{ml}$ with $0.1 \mathrm{M} \mathrm{NaCl}$ and adding $5 \mathrm{ml}$ of $60 \%$ ice-cold sucrose. After briefly mixing by inversion, the sucrose mixture was spun at $1500 \times g$ for $3 \mathrm{~min}$ at room temperature. The floating top layer of $C$. elegans was quickly removed with a glass Pasteur pipette, moved into a new $15 \mathrm{ml}$ polypropylene Falcon tube, and washed twice in $15 \mathrm{ml} 0.1 \mathrm{M} \mathrm{NaCl}$ as before. The pellet was transferred to a $1.5 \mathrm{ml} \mathrm{screw} \mathrm{cap} \mathrm{Eppendorf} \mathrm{tube} \mathrm{and} \mathrm{spun} \mathrm{at} 1500 \times \mathrm{g}$ for $1 \mathrm{~min}$ at room temperature in a swinging bucket centrifuge. The excess liquid was removed, and the C. elegans pellet was frozen in liquid nitrogen and stored at $-80^{\circ} \mathrm{C}$. Pellets were usually $250-750 \mu$ l.

\section{Preparation of lysates and fractionation of small-scale liquid cultures of C. elegans}

For lysis and fractionation, the C. elegans pellets were resuspended to $2 \mathrm{ml}$ in HBS (50 mM HEPES, pH 7.2, $100 \mathrm{~mm} \mathrm{NaCl}$ ). The $2 \mathrm{ml}$ of resuspended pellet was split into two $1 \mathrm{ml}$ aliquots in $2 \mathrm{ml}$ straight-walled polypropylene tubes (DOT Scientific). One milliliter of $2 \times$ lysis buffer (HBS with 2 mu PMSF, $2 \mu \mathrm{g} / \mu \mathrm{l}$ leupeptin, and $2 \mu \mathrm{g} / \mu \mathrm{l}$ pepstatin) was added to the first sample, and $1 \mathrm{ml}$ of $2 \times$ lysis buffer plus $2 \%$ Triton $\mathrm{X}-100$ was added to the second sample. Samples were lysed by three rounds of sonication on ice using a sonic dismembrator (Fisher Scientific, model 500) equipped with a microtip probe using power output set just below the microtip limit, three times for $20 \mathrm{~s}$, and a program in which the $20 \mathrm{~s}$ process times occurred in $2 \mathrm{~s}$ pulses separated by $2 \mathrm{~s}$ to allow the sample to cool. Debris was removed by centrifugation at $800 \times g$ for $10 \mathrm{~min}$ at $4^{\circ} \mathrm{C}$. The soluble fraction was separated from the membrane fraction using a $30 \mathrm{~min} 100,000 \times \mathrm{g}$ spin in a TLA 120.2 rotor at $4^{\circ} \mathrm{C}$ in a tabletop Beckman ultracentrifuge. The resulting pellet was resuspended in $1 \mathrm{ml}$ lysis buffer by Dounce homogenization. Total worm lysate protein concentration was measured by Bradford assay and equal volumes (50 $\mu \mathrm{g}$ of protein in the total lysate) of the total lysate, soluble fraction, and pellet fraction were analyzed by $10 \%$ SDS-PAGE.

Gels were transferred to nitrocellulose for immunoblotting. The top half of each blot (above the $45 \mathrm{kDa}$ marker) was incubated with 1:1000 rabbit anti-AGS-3 antibody, and the bottom half of each blot (below the $45 \mathrm{kDa}$ marker) was incubated with 1:1000 rabbit anti-GOA-1 antibody (Patikoglou and Koelle, 2002) and 1:10,000 rabbit anti-UNC-64 antibody (a gift from Mike Nonet, Washington University, St. Louis, MO). The secondary antibody used for all blots was 1:6000 goat anti-rabbit HRP-conjugated antibody (Biorad). Proteins were detected using chemiluminescence reagents (SuperSignal West Pico chemiluminescent substrate, Pierce).

\section{Food deprivation in C. elegans liquid cultures}

For acute starvation of $C$. elegans liquid cultures, well fed $20 \mathrm{ml}$ cultures were grown for 3-4 d, and animals were separated from HB101 bacteria using a sucrose float as described (see above, Small-scale liquid culture of C. elegans). After the washing following the sucrose float, $75 \%$ of the animals were put back into $15 \mathrm{ml}$ of supplemented growth medium in a $125 \mathrm{ml}$ Erlenmeyer flask containing no bacterial food with shaking at 180 $\mathrm{rpm}$, a temperature of $20^{\circ} \mathrm{C}$. Aliquots of $5 \mathrm{ml}$ were prepped at 1,2 , or $3 \mathrm{~h}$. Animals were prepared for lysis using the sucrose float method as usual. As a control, an additional aliquot of the animals was obtained from the sucrose float for the effects of the sucrose float preparation, and an additional culture of animals was placed in $5 \mathrm{ml}$ of growth medium with $1 \mathrm{ml}$ of concentrated HB101 bacteria and incubated for $3 \mathrm{~h}$ with shaking at 180 $\mathrm{rpm}$ and a temperature of $20^{\circ} \mathrm{C}$. This fed culture was prepped along side the food-deprived cultures. All cultures were lysed and fractionated as described (see above, Protein expression and purification).

\section{Dye filling to stain C. elegans amphid neurons}

The lipophilic tracer DiD (Invitrogen) was used to label a subset of head sensory neurons, including the ASH neurons. DiD at $2 \mathrm{mg} / \mathrm{ml}$ in dimethyl formamide was diluted 1:2000 in M9 buffer. Staged animals $(24 \mathrm{~h}$ post-L4) were picked into a microtiter well containing $150 \mu \mathrm{l}$ of diluted DiD. After incubation in the dye for $3 \mathrm{~h}$, animals were pipetted onto a seeded NGM plate to destain for $1 \mathrm{~h}$.

\section{ASH-specific protein expression and RNAi}

The osm-10 promoter (Hart et al., 1999; Ezak and Ferkey, 2010) was used for ASH-specific protein expression and RNAi experiments. For ASHspecific rescue, cDNAs were cloned behind the osm-10 promoter, and these constructs were injected at $50 \mathrm{ng} / \mu \mathrm{l}$. For ASH-specific RNAi (as described by Esposito et al., 2007), RIC-8 cDNA was inserted behind the osm-10 promoter in both the sense direction and antisense direction, and these constructs were coinjected at $100 \mathrm{ng} / \mu \mathrm{l}$ each. 


\section{Results}

C. elegans AGS-3 is biochemically similar to its mammalian and Drosophila homologs

In addition to having one or more C-terminal GPR domains, members of the Activator of G Protein Signaling 3 (AGS3) family of proteins, including mammalian AGS3 (Takesono et al., 1999) and LGN (mPins) (Mochizuki et al., 1996), Drosophila Pins (Yu et al., 2000), and C. elegans AGS-3 (Cuppen et al., 2003), GPR-1, and GPR-2 (Gotta et al., 2003; Srinivasan et al., 2003), also contain N-terminal tetratricopeptide repeats (TPR), which are thought to act as a protein scaffolding domain. AGS-3 is the sole C. elegans protein that, like mammalian AGS3 and LGN and Drosophila Pins, has seven TPR motifs and multiple GPR domains (Fig. 1A). AGS-3 shows identities of up to $65 \%$ with the mammalian proteins within these regions (Fig. $1 A$ ), but little conservation elsewhere. AGS-3 is not a clear ortholog of either AGS3 or LGN, as it is equally related to both but is far more closely related to them than are the two other $C$. elegans AGS3 family proteins, GPR-1/2 (Fig. $1 B$ ).

We used an in vitro pull-down assay to examine the interactions between purified GST-AGS-3 fusion proteins and purified GOA-1 (hereafter referred to as $\mathrm{G} \alpha$, the only widely expressed C. elegans $\mathrm{G} \alpha_{\mathrm{i} / \mathrm{o}}$ protein and a candidate target for AGS-3) (Fig. 1C,D). We found that full-length GST-AGS-3 bound to only $\mathrm{G} \alpha_{\mathrm{o}}$-GDP, the inactive state of the $G$ protein, while the C-terminal fragment of AGS-3 containing the four GPR domains could additionally bind $\mathrm{G} \alpha_{\mathrm{o}}-\mathrm{GTP}$, the activated state. Thus, the $\mathrm{G} \alpha$ binding activity of full-length AGS-3 is similar to that of mammalian AGS3 and LGN and Drosophila Pins (Mochizuki et al., 1996; Takesono et al., 1999; Schaefer et al., 2000; Bernard et al., 2001; Kopein and Katanaev, 2009). The C-terminal GPR fragment of Pins also has the G $\alpha$-GTP binding activity we saw for the GPR fragment of AGS-3 (Kopein and Katanaev, 2009). In Pins, this activity is masked in the full-length protein by an interaction between the TPR and GPR repeats. While binding activities of the GPR fragments of AGS3 and LGN have not yet been studied, the intramolecular TPR/GPR interaction in LGN has been demonstrated (Du and Macara, 2004; Nipper et al., 2007).Together, our results suggest that $C$. elegans AGS-3 is biochemically similar to its homologs, and that the study of AGS-3 in $C$. elegans may provide insight into the roles of these proteins in higher organisms.

\section{Like $\mathrm{G} \alpha_{\mathrm{o}}, a g s-3$ is widely expressed in C. elegans}

A transgene expressing GFP under the control of the ags-3 promoter was used to identify the cells that express AGS-3. GFP expression was seen in most or all adult neurons (Fig. $2 A$ ), including neurons in the head (Fig. 2B), tail (Fig. 2C), egg-laying system, along the ventral and dorsal nerve cords, and in muscles, including body wall muscles, egg-laying muscles, and pharyngeal muscles (Fig. 2D). The expression of AGS-3 in postmitotic cells suggests a role for this protein outside of the well studied functions of AGS3 family protein in regulating asymmetric cell division. In addition, the cells that express AGS-3 are almost identical to those that express $\mathrm{G} \alpha_{\mathrm{o}}$ (Mendel et al., 1995; Ségalat et al., 1995), suggesting that the two proteins could interact in vivo.

\section{Animals lacking AGS-3 are grossly wild type when given unlimited access to food}

We next examined animals lacking AGS-3 for defects in $\mathrm{G} \alpha_{\mathrm{o}}$ signaling. We obtained five ags-3 gene deletion mutants (Fig. 3A), four of which are putative null mutants because they fail to express detectable AGS-3 protein by Western blot analysis (Fig. 3B). When grown in standard laboratory conditions, which include unlimited access to food in the form of a bacterial lawn, the ags-3 mutants are healthy and show grossly normal body morphology and brood size (data not shown). In C. elegans, signaling through $\mathrm{G} \alpha_{\mathrm{o}}$ inhibits locomotion and egg-laying behavior (Mendel et al., 1995; Ségalat et al., 1995). While animals lacking functional $\mathrm{G} \alpha_{\mathrm{o}}$ move in a loopy pattern (Fig. 3C,D) and accumulate few unlaid eggs due to increased egg-laying behavior (Fig. $3 F, G$ ), ags-3 mutants move with a wild-type sinusoidal pattern (Fig. $3 E$ ) and retain a normal number of unlaid eggs (Fig. $3 H$ ). Thus, we did not observe defects in behaviors controlled by $\mathrm{G} \alpha$ o signaling in animals lacking AGS-3, provided the animals had unlimited access to food. 

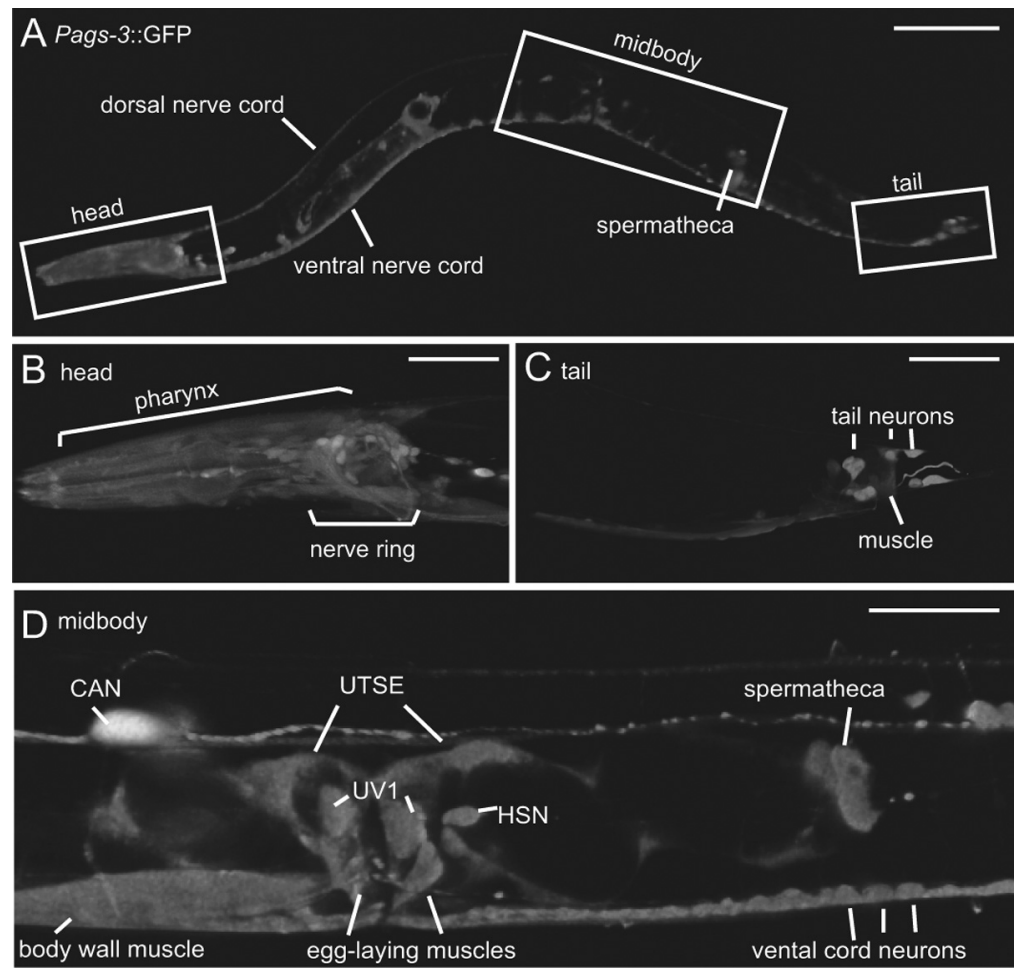

Figure 2. ags-3 is expressed in most or all neurons and muscles. $\boldsymbol{A}$, The $3.8 \mathrm{~kb}$ promoter and $2 \mathrm{~kb} 3^{\prime}-$ UTR regions of ags- 3 genomic DNA were used to drive expression of GFP in living worms. Representative image of GFP expression in a whole animal is shown. Scale bar, $100 \mu \mathrm{m} . \boldsymbol{B}-\boldsymbol{D}$, Representative images of specific body regions shown at higher magnification. Scale bar, $50 \mu \mathrm{m}$. Specific structures and cells expressing GFP are indicated in each panel.

\section{Animals lacking AGS-3 or $\mathrm{G} \alpha_{\mathrm{o}}$ fail to change several behaviors after food deprivation}

$\mathrm{G} \alpha_{\mathrm{o}}$ signaling modulates a number of behaviors in response to food deprivation, and we noticed that animals lacking AGS-3 were defective in these food deprivation responses. After 20-30 min of food deprivation, wild-type animals delay their response to the aversive stimulus dilute octanol, allowing them to continue searching for food (Chao et al., 2004), switch to searching for food over a wide area rather than a restricted area (Hills et al., 2004), and stop egg-laying behavior to protect their progeny (Dong et al., 2000). Altering these behaviors presumably increases the survival of the animals and their progeny.

We found that AGS-3 and $\mathrm{G} \alpha$ o were required to delay response to dilute octanol after food deprivation. With unlimited access to food, wild-type animals, ags-3 mutants, and $\mathrm{G} \alpha_{\mathrm{o}} \mathrm{mu}-$ tants responded to presentation of $30 \%$ octanol by backing away within 2-4 s. After 12-20 min of food deprivation, wild-type animals delayed their reversal response until 8-10 s after octanol presentation (Fig. 4A). This effect requires dopamine and is defective in the dopamine-deficient cat-2 mutant (Ezak and Ferkey, 2010). Mutants lacking either AGS-3 or G $\alpha_{\mathrm{o}}$, like cat-2mutants, continued to respond to dilute octanol within $4 \mathrm{~s}$ both in the presence of food and after food deprivation (Fig. 4A). We note that under all conditions $\mathrm{G} \alpha$ o mutants responded to octanol faster than did the wild type, which was likely a manifestation of the overall hyperactive locomotion of $\mathrm{G} \alpha_{\mathrm{o}}$ mutants. A double mutant lacking both AGS-3 and $\mathrm{G} \alpha_{\mathrm{o}}$ was indistinguishable from the $\mathrm{G} \alpha_{\mathrm{o}}$ single mutant (Fig. $4 A, p=1$ ).

Animals lacking either $\mathrm{G} \alpha$ o or AGS-3 also failed to properly change their food-seeking strategy after food deprivation. We quantified this by counting the frequency at which animals made high-angle turns (Hills et al., 2004). Fed wild-type animals seek food in a restricted area by turning frequently. By $30 \mathrm{~min}$ after removal from food, they switch to seeking food over a wider area by turning less frequently (Fig. $4 B)$. Dopamine is also involved in this behavioral switch (Hills et al., 2004), and food-deprived cat-2 mutants continue to make frequent high-angle turns. We found that animals lacking AGS-3 or G $\alpha_{\mathrm{o}}$, like cat-2 mutants, sought food in a wildtype manner when fed, but after food deprivation made many high-angle turns and thus continued to seek food in a restricted area (Fig. $4 B$ ). Loss of $\mathrm{G} \alpha_{\mathrm{o}}$ caused a complete defect in changing foodseeking behavior after food deprivation, while loss of AGS-3 caused only a partial defect. Two independent null alleles of ags-3 both showed partial defects (Fig. $4 B$ ), and the difference between the two alleles was not statistically significant $(p=0.17)$. We also tested a double mutant lacking both AGS-3 and $\mathrm{G} \alpha_{\mathrm{o}}$ (Fig. $4 B$ ) and found it to be indistinguishable from the $\mathrm{G} \alpha$ o single mutant $(p=0.09)$.

After 60 min of food deprivation, wildtype animals almost completely stopped egg-laying behavior (Fig. 4C). However, both $\mathrm{G} \alpha_{\mathrm{o}}$ mutants and ags-3 mutants continued to lay eggs after $60 \mathrm{~min}$ of food deprivation, albeit at reduced rates (Fig. $4 C)$. Two different null alleles of ags-3 both showed similar partial defects in stopping egg-laying behavior after food deprivation (Fig. $4 C$ ), and the difference between the two alleles was not statistically significant $(p=0.07)$. Assays of egg-laying behavior in $\mathrm{G} \alpha_{\mathrm{o}}$ mutants are complicated by the fact that these mutants produce few eggs and thus are able to lay few eggs even when fed. To get around this problem, we transgenically expressed pertussis toxin specifically in the egg-laying motor neurons to inactivate $\mathrm{G} \alpha_{\mathrm{o}}$ in these cells without affecting egg production of the animals (Tanis et al., 2008). This prevented the egg-laying shut off upon food deprivation (Fig. 4C). We also tested a double mutant lacking both AGS-3 and $\mathrm{G} \alpha_{\mathrm{o}}$ (Fig. $4 C$ ) and found it to be indistinguishable from the $\mathrm{G} \alpha_{\mathrm{o}}$ single mutant $(p=0.9$ ).

In summary, AGS-3 and $\mathrm{G} \alpha_{\mathrm{o}}$ mutants were defective in their ability to alter three different behaviors in response to food deprivation. This suggests the two proteins may generally function together to alter a wide variety of behaviors in food-deprived animals. We note that AGS-3 mutants showed a reduced response to food deprivation in some behavioral assays (Fig. 4B,C and data not shown), so AGS-3 is not absolutely required for all responses to food deprivation.

\section{AGS-3 protein moves to a Triton-soluble pellet fraction after food deprivation}

AGS3 family proteins show regulated localization to the cell cortex during their functions in asymmetric cell division (Yu et al., 2000; Du et al., 2001; Blumer et al., 2002; Couwenbergs et al., 2004; David et al., 2005; Hampoelz et al., 2005; Sanada and Tsai, 2005; Wang et al., 2005). We used biochemical fractionation to see whether AGS-3 might show analogous regulation upon food deprivation. In whole-worm lysates, $\mathrm{G} \alpha$ o pellets with the plasma membrane after a $100,000 \times g$ spin but can be solubilized by the 
addition of the nonionic detergent Triton X-100 (Patikoglou and Koelle, 2002). We found that AGS-3 was in the $100,000 \times g$ pellet of fractionated worm lysates in the absence of detergent (data not shown) but could not be solubilized by the addition of detergent (Fig. 5, lanes 1-3). In contrast, C. elegans syntaxin (UNC-64), a transmembrane protein used as a control, was efficiently solubilized by detergent. Thus in the presence of food AGS-3 is associated with a detergent-insoluble structure.

AGS-3 progressively moved into a Triton $\mathrm{X}-100$-soluble fraction during food deprivation (Fig. 5, lanes 4-12). After $2 \mathrm{~h}$ of food deprivation, a significant amount of AGS-3 was reproducibly seen in the detergent-soluble fraction (Fig. 5, compare lanes 2 and 8), and in some repetitions of this experiment, a small amount of AGS-3 was present in the soluble fraction after only $1 \mathrm{~h}$ (data not shown). By $3 \mathrm{~h}$ of food deprivation, about half of the AGS-3 protein had moved into the detergent-soluble fraction (Fig. 5, lane 11). When the worm culture was allowed to slowly starve over a period of days, the large majority of AGS-3 was found in the detergent-soluble fraction (data not shown). In the absence of detergent, AGS-3 was found in the pellet fraction in both fed and food-deprived conditions (Fig. 5, lane 15). The control protein UNC-64 did not change its fractionation pattern upon food deprivation (Fig. 5, bottom blots).

These results show that food deprivation causes a physical change in the AGS-3 protein that is manifested by alteration of its biochemical fractionation. Since AGS-3 mutants only begin to show behavioral defects upon food deprivation, this suggests that the physical change in AGS-3 upon food deprivation may allow it to function with $\mathrm{G} \alpha$ o to alter behavior.

\section{AGS-3 acts via RIC-8 to activate $\mathrm{G} \boldsymbol{\alpha}_{\mathrm{o}}$ in the ASH} chemosensory neurons to slow octanol avoidance

We analyzed the mechanism by which AGS-3 affects octanol avoidance, the C. elegans behavior whose food modulation is best characterized. When the ASH chemosensory neurons sense octanol they release glutamate onto interneurons to cause an avoidance response (Chao et al., 2004). The feeding state of the animal affects the release of neurotransmitters that signal onto the ASHs to activate several $\mathrm{G}$ proteins that alter ASH function (Wragg et al., 2007; Harris et al., 2009, 2010; Ezak and Ferkey, 2010). Among these, $\mathrm{G} \alpha_{\mathrm{o}}$ acts by inhibiting glutamate release from ASHs (Esposito et al., 2010; Harris et al., 2010). We found that the AGS-3 is expressed in ASH (Fig. 6A-C), suggesting that AGS-3 functions with $\mathrm{G} \alpha_{\mathrm{o}}$ in these neurons after food deprivation to delay octanol avoidance.

To investigate the function of AGS-3 and $\mathrm{G} \alpha$ in the ASHs, we used a cell-specific promoter that allowed us to express transgenes specifically in these neurons (Fig. 6D) and assayed effects on octanol avoidance. Wild-type animals expressing the control protein GFP in their ASHs responded normally to octanol (Fig. $6 E$, bars 1,2$)$. However, expression of pertussis toxin to specifi- cally inactivate $\mathrm{G} \alpha_{\mathrm{i} / \mathrm{o}}$ in the ASHs of wild-type animals made these animals respond rapidly to dilute octanol after food deprivation (Fig. 6E, bars 3, 4). G $\alpha_{\mathrm{o}}$ mutant animals showed a similar rapid response (Fig. $6 E$, bars 5, 6), but re-expression of either wild-type $\mathrm{G} \alpha_{\mathrm{o}}$ (Fig. $6 E$, bars 7, 8) or activated $\mathrm{G} \alpha_{\mathrm{o}}(\mathrm{Q} 205 \mathrm{~L}$ ) (Fig. $6 E$, bars 9,10$)$ in the ASHs slowed their response to octanol after food deprivation. The underlying hyperactive locomotion of $\mathrm{G} \alpha$ mutants likely prevented this ASH-specific rescue from slowing the response completely to wild-type levels. These results show that $\mathrm{G} \alpha_{\mathrm{o}}$ is both necessary and sufficient in the ASHs to inhibit octanol response after food deprivation. Expression of activated $\mathrm{G} \alpha_{\mathrm{o}}(\mathrm{Q} 205 \mathrm{~L})$ in the ASHs slowed the response to octanol even in the presence of food, an apparent gain-of-function effect (Fig. $6 E$, bars 9, 10). Combined with the earlier results, this suggests that it is the activated GTP-bound $\mathrm{G} \alpha$ o subunit, and not signaling by $G \beta \gamma$, that is responsible for slowing the response to dilute octanol. Finally, expression of the N150I GPR-insensitive mutant of $\mathrm{G} \alpha_{\mathrm{o}}$ (Willard et al., 2008) in the ASHs was unable to rescue the octanol avoidance defect of $\mathrm{G} \alpha_{\mathrm{o}}$ mutants (Fig. $6 E$, bars 11, 12). This GPR-insensitive G $\alpha_{\text {o }}$ protein cannot bind to AGS-3 but can still bind other proteins in a nucleotide-dependent manner (data not shown). This result suggests that the mechanism by which food deprivation slows response to octanol involves interaction between the GPR domains of AGS-3 and G $\alpha_{\mathrm{o}}$ in the ASH neurons.

Expression of AGS-3 in the ASHs of ags-3 mutants was sufficient to rescue the effects of food deprivation on octanol response in these mutants (Fig. 6F, bars 5,6). In fact, expression of the C-terminal half of AGS-3 containing the four GPR domains was sufficient for rescue (Fig. 6F, bars 7, 8). 
A Reversal response to dilute octanol

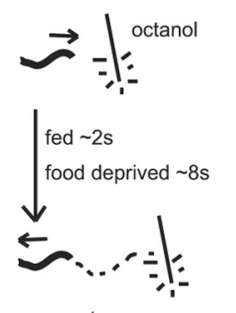

reversal response

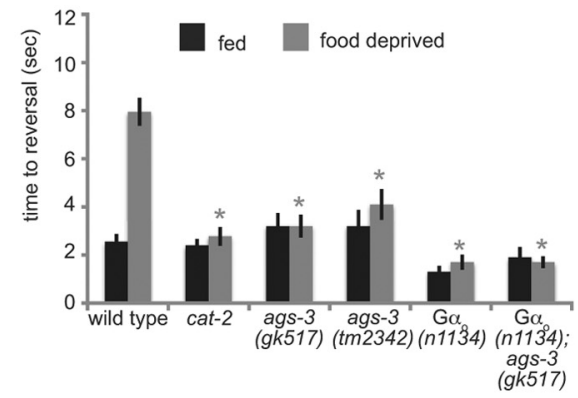

B Area restricted search
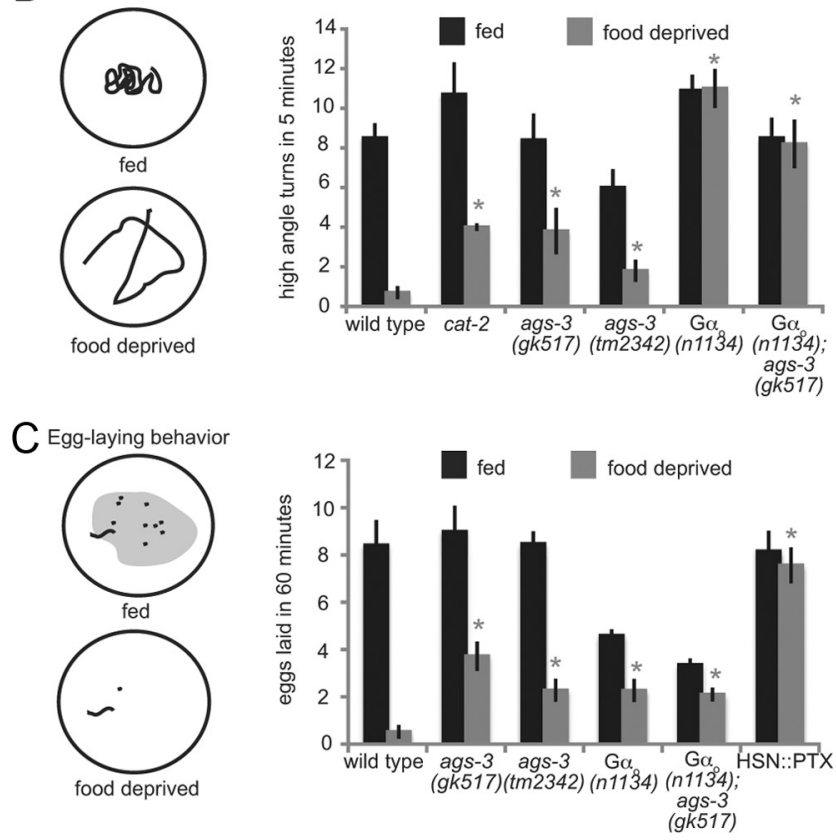

Figure 4. ags-3 mutants fail to show effects of food deprivation on several behaviors. $\boldsymbol{A}$, Reversal response to dilute octanol. After 12-20 min in the presence or absence of food, forward-moving animals were presented with $30 \%$ octanol, and the number of seconds to reversal after octanol presentation was counted in wild-type or the indicated mutant animals. Diagram at left depicts wild-type response to $30 \%$ octanol; $n=10$ animals for each measurement. $\boldsymbol{B}$, Area-restricted search. Individual animals were moved to a plate without food, and the number of high-angle turns in 5 min was counted (fed condition). After an additional 25 min, the number of high-angle turns in 5 min was counted again (food-deprived condition). Diagram at left schematizes the path a wild-type animal takes on an agar plate before and after food deprivation; $n=10$ animals for each genotype. $\boldsymbol{C}$, Egg laying. Adult animals were placed on a plate with or without food and allowed to lay eggs for $1 \mathrm{~h}$. After $1 \mathrm{~h}$, the adults were removed and the number of laid eggs was counted. Diagram at left depicts wild-type egg-laying behavior when fed or food-deprived, with the worm and laid eggs (dots) schematized on an agar plate. HSN::PTX animals transgenically express pertussis toxin in the HSN egg-laying motor neurons; $n=100$ animals for each genotype in each condition. In all panels, error bars are $95 \%$ confidence intervals and asterisks indicate statistical differences from wild-type food-deprived condition; $p<0.05$, Student's two-tailed $t$ test.

The above results suggest AGS- 3 and $\mathrm{G} \alpha_{\mathrm{o}}$ function together in the ASHs but do not provide information about whether AGS-3 produces active $\mathrm{G} \alpha_{\mathrm{o}}$-GTP or whether AGS-3 rather acts as a downstream effector of $\mathrm{G} \alpha_{\mathrm{o}}$-GTP signaling. To resolve this issue, we performed genetic epistasis experiments using combinations of loss-of-function mutants and ASH-specific overexpression of proteins. Expression of activated $\mathrm{G} \alpha_{\mathrm{o}}(\mathrm{Q} 205 \mathrm{~L})$ in the ASHs of wild-type animals caused a strong gain-of-function phenotype in which animals responded slowly to octanol even in the presence of food (Fig. 6G, bars 5, 6). In ags-3 null mutant animals, expression of activated $\mathrm{G} \alpha_{\mathrm{o}}(\mathrm{Q} 205 \mathrm{~L})$ caused the same gain-of-function

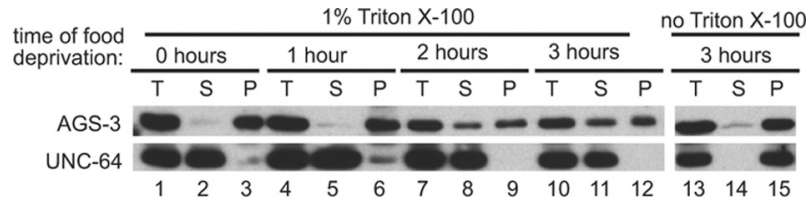

Figure 5. Upon food deprivation, AGS-3 moves to a Triton X-100-soluble pellet fraction. Western blot of fractionated wild-type worm lysates after food deprivation for $0,1,2$, or $3 \mathrm{~h}$. Blots were probed with antibodies to AGS-3 (top) and antibodies to UNC-64 (bottom). UNC-64 is a transmembrane protein used as a Triton-soluble control. T, Total lysate; S, soluble fraction; $P$, pellet fraction. Results shown here are representative of five experiments.

phenotype (Fig. $6 G$, bars 7,8 ). We found that overexpression of AGS-3 in the ASHs of wild-type animals caused a gain-offunction phenotype similar to that seen in animals expressing $\mathrm{G} \alpha_{\mathrm{o}}(\mathrm{Q} 205 \mathrm{~L})$ (Fig. 6G, bars 11, 12). However, this overexpression of AGS-3 had no effect in $\mathrm{G} \alpha_{\mathrm{o}}$ loss-of-function mutant animals; these animals behaved just like $\mathrm{G} \alpha_{\mathrm{o}}$ mutants without the AGS-3 transgene (Fig. 6G, bars 13, 14). Thus two different epistasis experiments gave results inconsistent with the possibility that AGS-3 acts downstream of $\mathrm{G} \alpha_{\mathrm{o}}$ and instead suggest that AGS-3 activates $\mathrm{G} \alpha_{\mathrm{o}}$.

Previous studies have shown RIC- 8 can activate G $\alpha$ that is bound to AGS3 family proteins (Tall and Gilman, 2005; Thomas et al., 2008) but not when $\mathrm{G} \alpha$ is bound to $\mathrm{G} \beta \gamma$ (Tall et al., 2003), although Ric-8A is most efficient at activating free $\mathrm{G} \alpha$ (Tall and Gilman, 2005; Thomas et al., 2008). Therefore we next asked whether and how RIC-8 acts to mediate the effects of food deprivation on octanol avoidance. Overexpression of RIC-8 specifically in the ASHs of wild-type animals caused a delay in octanol avoidance response even in the presence of food, similar to expression of activated $\mathrm{G} \alpha_{\mathrm{o}}$ or overexpression of AGS-3 (Fig. $6 \mathrm{H}$, bars 3,4 ). Overexpression of RIC-8 in either $a g s-3$ or $\mathrm{G} \alpha_{\mathrm{o}}$ mutant animals had no effect (Fig. $6 \mathrm{H}$, bars 5-12). We also saw that RNAi knock-down of RIC-8 by expression of double-stranded ric-8 RNA in the ASHs (Esposito et al., 2007) caused rapid octanol avoidance after food deprivation similar to that seen in ags-3 and $\mathrm{G} \alpha_{\mathrm{o}}$ mutant animals (Fig. 6I, bars 3, 4). The effect of overexpressing AGS-3 required RIC-8, since it had no effect in RIC-8 knockdown animals (Fig. 6I, compare bars 4 and 8). Finally, activated $\mathrm{G} \alpha_{\mathrm{o}}(\mathrm{Q} 205 \mathrm{~L})$ still caused a gain-of-function effect in RIC-8 knockdown animals (Fig. 6I, bars 9-12). These results suggest that after food deprivation, AGS-3 and RIC-8 act together in a mutually dependent fashion upstream of $\mathrm{G} \alpha_{\mathrm{o}}$ to promote activation of $\mathrm{G} \alpha_{\mathrm{o}}$, which in turn slows response to octanol.

\section{Discussion}

\section{AGS-3 mediates behavioral responses to food deprivation}

We found that three different C. elegans behaviors absolutely or partially require AGS-3 activity to respond to food deprivation. These three behaviors depend on different neural circuits and neurotransmitters (Dong et al., 2000; Chao et al., 2004; Hills et al., 2004; Gray et al., 2005). In addition, we found that AGS-3 is expressed in most or all neurons and many muscles, and that food deprivation causes a physical alteration in AGS-3 protein manifested as a change in its Triton X-100 solubility. Because this fractionation change is seen in whole-animal lysates, the change in AGS-3 protein upon food deprivation must happen in most, if not all, AGS-3-expressing cells. Together, these results suggest that AGS-3 mediates a wide variety of responses to food deprivation in C. elegans.

Given that AGS3 proteins are highly conserved from C. elegans to mammals, it is of interest to consider whether mammalian 
AGS3 proteins also mediate behavioral changes after food deprivation. The principal defect seen in AGS3 knock-out mice was a lean phenotype due to increased metabolism (Blumer et al., 2008). Signaling molecules that alter metabolism are generally also involved in altering feeding behaviors (Gruninger et al., 2007), although the AGS3 knock-out mice did not alter their food intake under the ad libitum feeding conditions used. We note, however, that we saw effects of AGS-3 in C. elegans only after food deprivation, a condition under which AGS3 knock-out mice were not tested. Another link connecting mammalian AGS3 with feeding is based on studies showing that AGS3 expression in rodents is altered by drugs of abuse and that AGS3 appears to mediate neuroplasticity, leading to withdrawal and reinstatement (Bowers et al., 2004). Because the signaling pathways that mediate effects of drugs of abuse also mediate effects of feeding and food deprivation (Pandit et al., 2011), it would not be surprising to find that mammalian AGS3 modulates signaling under different feeding states.

\section{Food deprivation induces a physical change in AGS-3 protein}

The progressive increase in AGS-3 detergent solubility upon food deprivation could reflect its release from a detergent-insoluble membrane domain or cytoskeletal structure that activates or frees AGS- 3 to activate $\mathrm{G} \alpha$. The association of AGS-3 with a detergentinsoluble structure could be mediated by its N-terminal TPR motifs. Yeast two-hybrid studies with the $\mathrm{N}$-terminal TPR domain of mammalian AGS3 have identified putative binding partners, including cytoskeletonassociated proteins (An et al., 2008). The role of most of these binding partners in AGS3 function remains untested, but many of the proteins are conserved in C. elegans and their functions in response to food deprivation can be determined through the same type of genetic studies presented here.

While changes in the detergent solubility of AGS-3 from whole-worm lysates occur over the course of several hours of food deprivation, the AGS-3-dependent behavioral changes we describe occur within $15 \mathrm{~min}$ of food deprivation. It is possible that the physical change to AGS-3 happens faster in certain cells, such as the ASHs, so that some behaviors are altered on shorter time scales than others. Alternatively, it is possible that AGS-3 mediates behavioral responses to short-term food deprivation in one way and mediates additional responses to long-term food de-
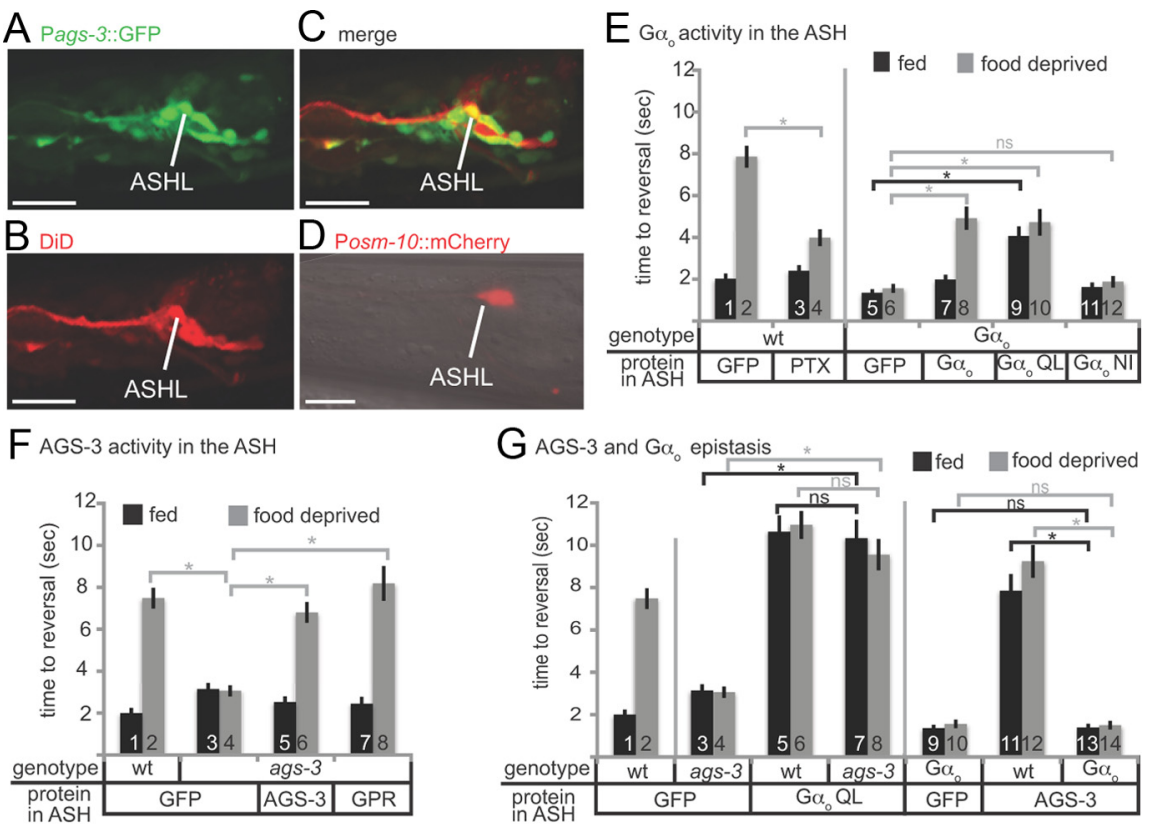

G AGS-3 and $\alpha_{\circ}$ epistasis

H RIC-8 overexpression in the ASH
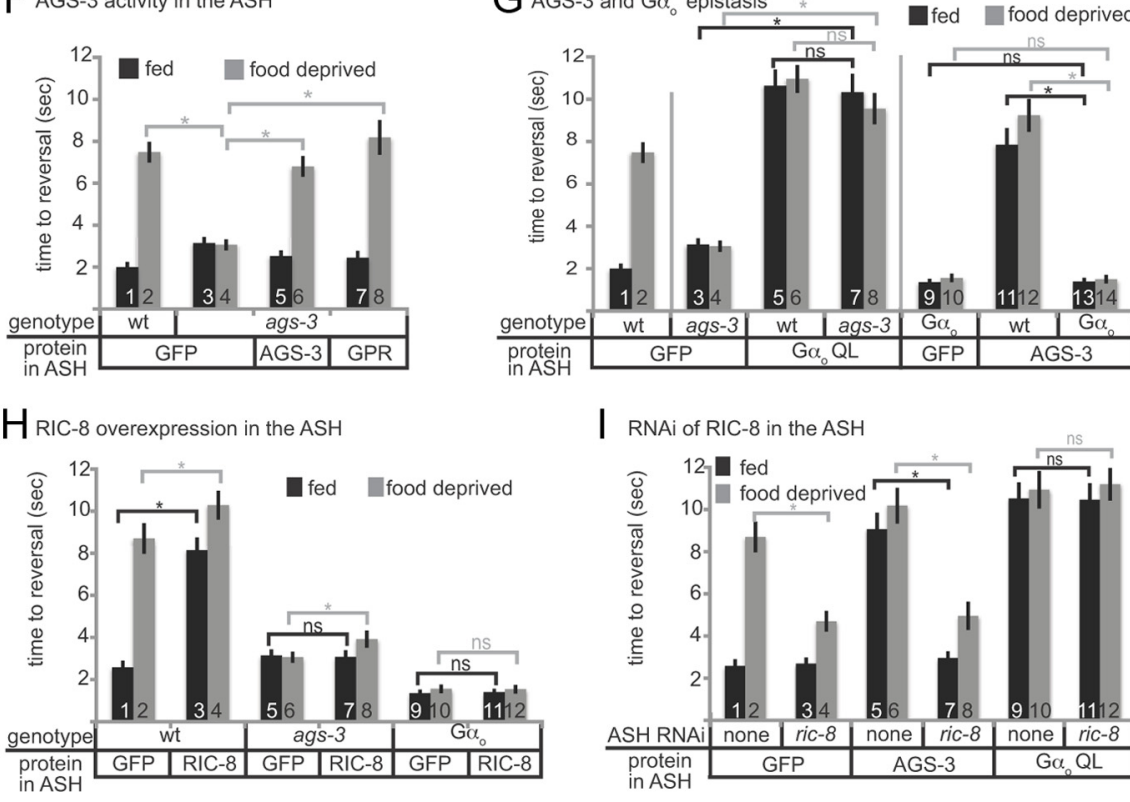

I RNAi of RIC-8 in the ASH

Figure 6. AGS-3, G $\alpha_{0}$, and RIC-8 act in the ASH to mediate the effects of food deprivation on octanol avoidance. $A$, GFP fluorescence in the head under the control of the ags-3 promoter. $\boldsymbol{B}$, DiD fluorescent labeling of subset of head sensory neurons, including the ASHs. $\boldsymbol{C}$, Merge. D, The osm-10 promoter drives transgene expression (mCherry) specifically in the ASHs. Scale bars: $\boldsymbol{A}-\boldsymbol{D}, 20 \mu \mathrm{m} . \boldsymbol{E}, 0$ ctanol avoidance assays after ASH-specificinactivation of $\alpha_{0 / i}$ subunits with pertussis toxin (PTX) or re-expression of $G \alpha_{0}$, activated $G \alpha_{0}(\mathrm{Q} 205 \mathrm{~L})$, or GPR-insensitive $\mathrm{G} \alpha_{0}(\mathrm{~N} 150 \mathrm{I})$ in the ASHs of a $\mathrm{G} \alpha_{0}$ mutant. $\boldsymbol{F}$, Rescue of the ags-3 dilute octanol avoidance defect by ASH-specific expression of AGS-3 or its GPR-repeat fragment in ags-3 mutant animals. G, Epistasis between $\alpha_{0}$ and AGS-3 in the ASHs by combining loss-of-function mutants and ASH-specific overexpression of AGS-3 or $\mathrm{G} \alpha_{0}(\mathrm{Q} 205 \mathrm{~L})$. $\boldsymbol{H}$, Overexpression of RIC-8 in the ASHs and epistasis experiments combining this overexpression with loss of either AGS-3 or $\mathrm{G} \alpha_{0}$. I, ASH-specific RNAi of RIC-8 and epistasis experiments performed by combining this RNAi with overexpression of either AGS-3 or $\alpha_{0}(Q 205 \mathrm{~L})$. For $\boldsymbol{E}-\boldsymbol{I}$, asterisks indicate statistical difference with $p \leq 0.001$, black brackets compare fed conditions, gray brackets compare food-deprived conditions, error bars are $95 \%$ confidence intervals, $n=50$ (10 animals from each of 5 transgenic lines) for each bar, and $p$ values were calculated using a two-tailed Student's $t$ test. The mutants used were ags-3( gk517) and, for $\mathrm{G} \alpha_{0}$, goa-1(n1134). Control data expressing GFP in wild-type, ags-3 mutants, or G $\alpha_{o}$ mutants are replotted in more than one panel. wt, Wild type.

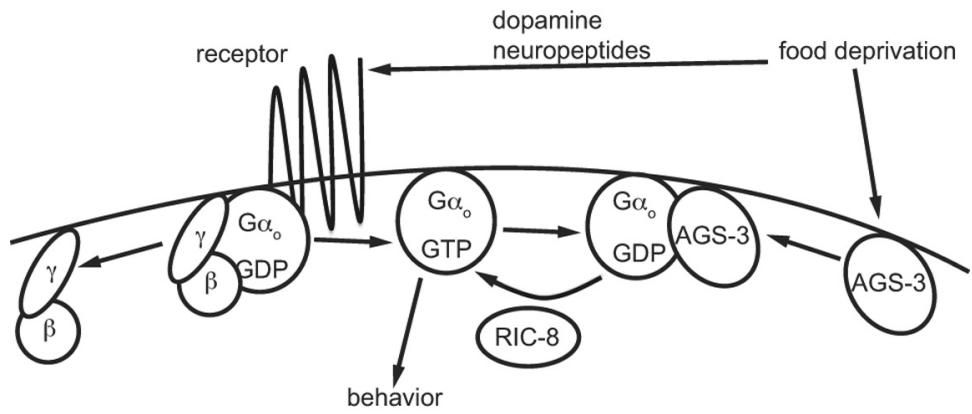

Figure 7. Model depicting a proposed mechanism by which AGS-3 and RIC-8 potentiate G $\alpha_{0}$ signaling to modify behaviors upon food deprivation. Release of neurotransmitters, including dopamine and neuropeptides, is modulated by food deprivation. Activated receptors for these signals catalyze GTP binding by $\mathrm{G} \alpha_{0}$, causing dissociation of $\mathrm{G} \beta \gamma$ and activation of G $\alpha_{0}$-GTP signaling. After $\mathrm{G} \alpha_{0}$ hydrolyzes GTP, it is prevented from reassociating with $\mathrm{G} \beta \gamma$ by binding AGS-3, which presents $G \alpha_{0}$ to RIC-8 for reactivation. This reactivation process can continue for additional cycles. Food deprivation causes a physical change in AGS-3 protein that increases its activity. 
privation in another manner involving the slower physical change to the AGS-3 protein. Although the TPR motifs of AGS-3 may be responsible for mediating the slow change in detergentsolubility after food deprivation, they are dispensable for AGS-3 activity in modulating octanol avoidance after food deprivation, since we found that expression of the GPR domains alone in the ASHs is sufficient to rescue the octanol avoidance defect of ags-3 mutants. Thus, it appears that the GPR domains of AGS-3 mediate behavioral responses to short-term food deprivation, perhaps by amplifying $\mathrm{G} \alpha$ o signaling in response to ligands like dopamine and neuropeptides that are released quickly upon food deprivation. The TPR motifs could be responsible for mediating responses to longer-term food deprivation by altering interactions of AGS-3 with detergent-insoluble structures. However, the relationship between the food deprivation-mediated change in AGS-3 solubility and the behavioral changes seen is only hypothetical, and further experiments are required to test whether there is a direct relationship between the change in AGS-3 solubility upon food deprivation and the changes in behavior that occur upon food deprivation.

\section{AGS-3 activates $\mathrm{G} \boldsymbol{\alpha}_{\mathrm{o}}$ signaling via RIC-8}

Previous in vitro studies of the interactions between $\mathrm{G} \alpha_{\mathrm{i} / \mathrm{o}}$ proteins and AGS3 family proteins were consistent with either the AGS3 protein inactivating $G \alpha$ signaling by acting as a guanine nucleotide dissociation inhibitor, or activating signaling by either G $\alpha$ or G $\beta \gamma$ (Natochin et al., 2000; Bernard et al., 2001; Kopein and Katanaev, 2009). Our work clearly shows that AGS-3 acts upstream of $\mathrm{G} \alpha$ o to activate signaling via the $\mathrm{G} \alpha$ subunit. Our results are consistent with genetic studies showing that AGS3 family proteins and $\mathrm{G} \alpha_{\mathrm{o}}$ promote the same effects on asymmetric cell divisions (Gotta et al., 2003; Srinivasan et al., 2003; Kopein and Katanaev, 2009). The work on asymmetric cell division in worms and flies showed the dependence of the AGS3 family proteins $\mathrm{G} \alpha_{\mathrm{o}}$, and Ric-8 on each other for localization (Afshar et al., 2005; David et al., 2005; Hampoelz et al., 2005; Wang et al., 2005), but it was unable to determine whether one protein activated the other or vice versa. This is because mutants for all three proteins showed similar defects, making double-mutant studies uninformative. We have overcome this difficulty by overexpressing wild type or activated forms of the proteins in the ASHs to generate gain-of-function defects in octanol avoidance opposite those seen in the loss-of-function mutants. Thus we were able to carry out genetic epistasis studies and show that in vivo AGS-3 and RIC-8 function in a mutually dependent fashion to activate $\mathrm{G} \alpha_{\mathrm{o}}$.

Using ASH-specific rescue of AGS-3 and $\mathrm{G} \alpha$, as well as ASHspecific inactivation of $\mathrm{G} \alpha$ o with pertussis toxin, we have shown that both AGS-3 and $\mathrm{G} \alpha_{\mathrm{o}}$ act in the ASHs to mediate the effects of food deprivation on octanol avoidance. Our evidence that RIC-8 also acts in the ASH is somewhat weaker. Overexpression using an ASH-specific promoter showed that RIC- 8 in the ASHs is sufficient to alter octanol avoidance. Because the almost complete paralysis of ric- 8 mutants made it impossible to assay them for octanol avoidance, we expressed double-stranded ric- 8 RNA in the ASH neurons to induce RNAi knockdown of ric- 8 in these cells and found that this did induce a defect in the effect of food deprivation on octanol avoidance. While Esposito et al. (2007) showed that RNAi gene silencing in the ASH did not spread to neighboring neurons, double-stranded RNA and the RNAi effect can spread from other cell types in C. elegans (Jose et al., 2009). Thus RNAi knockdown of ric-8 in the ASHs may not conclusively prove that RIC- 8 activity is required in these cells. However, given the strong evidence that AGS-3 and $\mathrm{G} \alpha_{\mathrm{o}}$ act specifically in the ASHs and that RIC-8 overexpression in the ASHs and RNAi induced in the ASHs both alter octanol avoidance, it is likely that AGS-3 and RIC-8 act together in the ASH neurons to activate $\mathrm{G} \alpha_{\mathrm{o}}$ activity upon food deprivation.

We propose that the general function of GPR domain proteins such as AGS-3 is to present $\mathrm{G} \alpha_{\mathrm{i} / \mathrm{o}}-\mathrm{GDP}$ to Ric- 8 for activation. In all cases analyzed by rigorous genetics, including work on asymmetric cell divisions in flies (Kopein and Katanaev, 2009), worms (Ashfar et al., 2004; Couwenbergs et al., 2004), and mammalian cells (Du and Macara, 2004) and in this work, every function of AGS3 family proteins requires Ric-8. We found that in the ASHs, AGS-3 function is completely dependent on the presence of RIC-8. In vitro, Ric- 8 is capable of activating $\mathrm{G} \alpha_{\mathrm{o}}$ by catalyzing exchange of GDP for GTP on either free G $\alpha$-GDP or a G $\alpha$-GDPGPR complex (Tall et al., 2003). However, our work suggests that the ability of Ric- 8 to act on free G $\alpha$-GDP is irrelevant in vivo, since RIC-8 activity in the ASHs is completely dependent on the presence of AGS-3. These in vivo and in vitro results can be reconciled using the further observations that Ric- 8 is incapable of activating $\mathrm{G} \alpha$-GDP that is in a heterotrimeric complex with $\mathrm{G} \beta \gamma$ (Tall et al., 2003) and that GPR domains bind to G $\alpha$ competitively with $\mathrm{G} \beta \gamma$ (Takesono et al., 1999; Bernard et al., 2001). These results suggest a model in which AGS- 3 binds $\mathrm{G} \alpha_{\mathrm{o}}$-GDP to prevent it from forming an inactive heterotrimer with $\mathrm{G} \beta \gamma$, thus preserving $\mathrm{G} \alpha$ in a form on which RIC- 8 can act.

Based on the above arguments, we propose a model in which AGS-3 and RIC-8 act to amplify and/or prolong $\mathrm{G} \alpha$ o signaling initiated by a ligand-activated, $G$ protein-coupled receptor (Fig. 7). This model is based on our studies of AGS-3 function in the ASH neurons of C. elegans to alter octanol avoidance after food deprivation, but it may serve as a general mechanism for response to food deprivation in other cells and other species. The model depicts food deprivation causing release of ligands whose signaling through $\mathrm{G} \alpha_{\mathrm{o}}$ is amplified by AGS-3, and food deprivation having a second input onto the AGS-3 protein to increase its activity and further amplify signaling. The balance between these two effects of food deprivation may vary for different circuits or time scales of food deprivation, providing the flexibility needed to explain the complex effects of food deprivation on behavior.

\section{References}

Afshar K, Willard FS, Colombo K, Siderovski DP, Gönczy P (2005) Cortical localization of the Galpha protein GPA-16 requires RIC-8 function during C. elegans asymmetric cell division. Development 132:4449-4459.

An N, Blumer JB, Bernard ML, Lanier SM (2008) The PDZ and band 4.1 containing protein Frmpd1 regulates the subcellular location of activator of G-protein signaling 3 and its interaction with G-proteins. J Biol Chem 283:24718-24728.

Bernard ML, Peterson YK, Chung P, Jourdan J, Lanier SM (2001) Selective interaction of AGS3 with G proteins and the influence of AGS3 on the activation state of G proteins. J Biol Chem 276:1585-1593.

Blumer JB, Chandler LJ, Lanier SM (2002) Expression and subcellular distribution of the two G-protein regulators AGS3 and LGN indicate distinct functionality. Localization of LGN to the midbody during cytokinesis. J Biol Chem 277:15897-15903.

Blumer JB, Lord K, Saunders TL, Pacchioni A, Black C, Lazartigues E, Varner KJ, Gettys TW, Lanier SM (2008) Activator of G protein signaling 3 null mice: I. Unexpected alterations in metabolic and cardiovascular function. Endocrinology 149:3842-3849.

Bowers MS, McFarland K, Lake RW, Peterson YK, Lapish CC, Gregory ML, Lanier SM, Kalivas PW (2004) Activator of G protein signaling 3: a gatekeeper of cocaine sensitization and drug seeking. Neuron 42:269-281.

Brenner S (1974) The genetics of Caenorhabditis elegans. Genetics 77:71-94.

Chao MY, Komatsu H, Fukuto HS, Dionne HM, Hart AC (2004) Feeding status and serotonin rapidly and reversibly modulate a Caenorhabditis elegans chemosensory circuit. Proc Natl Acad Sci U S A 101:15512-15517. 
Chase DL, Koelle MR (2004) Genetic analysis of RGS protein function in. Caenorhabditis elegans. Methods Enzymol 389:305-320.

Couwenbergs C, Spilker AC, Gotta M (2004) Control of embryonic spindle positioning and Galpha activity by C. elegans RIC-8. Curr Biol 14:1871-1876.

Cuppen E, van der Linden AM, Jansen G, Plasterk RH (2003) Proteins interacting with Caenorhabditis elegans Galpha subunits. Comp Funct Genomics 4:479-491.

David NB, Martin CA, Segalen M, Rosenfeld F, Schweisguth F, Bellaïche Y (2005) Drosophila Ric-8 regulates Galphai cortical localization to promote Galphai-dependent planar orientation of the mitotic spindle during asymmetric cell division. Nat Cell Biol 7:1083-1090.

Dong MQ, Chase D, Patikoglou GA, Koelle MR (2000) Multiple RGS proteins alter neural $G$ protein signaling to allow $C$. elegans to rapidly change behavior when fed. Genes Dev 14:2003-2014.

Du Q, Macara IG (2004) Mammalian Pins is a conformational switch that links NuMA to heterotrimeric G proteins. Cell 119:503-516.

Du Q, Stukenberg PT, Macara IG (2001) A mammalian Partner of inscuteable binds NuMA and regulates mitotic spindle organization. Nat Cell Biol 3:1069-1075.

Esposito G, Di Schiavi E, Bergamasco C, Bazzicalupo P (2007) Efficient and cell specific knock-down of gene function in targeted C. elegans neurons. Gene. 395:170-176.

Esposito G, Amoroso MR, Bergamasco C, Di Schiavi E, Bazzicalupo P (2010) The $\mathrm{G}$ protein regulators EGL-10 and EAT-16, the $\mathrm{G} \alpha_{\mathrm{i}} \mathrm{GOA}-1$ and the $\mathrm{G} \alpha_{\mathrm{q}}$ EGL-30 modulate the response of the $C$. elegans ASH polymodal nociceptive sensory neurons to repellents. BMC Biol 8:138.

Ezak MJ, Ferkey DM (2010) The C. elegans D2-like dopamine receptor DOP-3 decreases behavioral sensitivity to the olfactory stimulus 1-octanol. PLoS One 5:e9487.

Gotta M, Dong Y, Peterson YK, Lanier SM, Ahringer J (2003) Asymmetrically distributed C. elegans homologs of AGS3/PINS control spindle position in the early embryo. Curr Biol 13:1029-1037.

Gray JM, Hill JJ, Bargmann CI (2005) A circuit for navigation in. Caenorhabditis elegans. Proc Natl Acad Sci U S A 102:3184-3191.

Gruninger TR, LeBoeuf B, Liu Y, Garcia LR (2007) Molecular signaling involved in regulating feeding and other motivated behaviors. Mol Neurobiol 35:1-20.

Hampoelz B, Hoeller O, Bowman SK, Dunican D, Knoblich JA (2005) Drosophila Ric-8 is essential for plasma-membrane localization of heterotrimeric G proteins. Nat Cell Biol 7:1099-1105.

Harris G, Mills H, Wragg R, Hapiak V, Castelletto M, Korchnak A, Komuniecki RW (2010) The monoaminergic modulation of sensory-mediated aversive responses in $C$ elegans requires glutamatergic/peptidergic cotransmission. J Neurosci 30:7889-7899.

Harris GP, Hapiak VM, Wragg RT, Miller SB, Hughes LJ, Hobson RJ, Steven R, Bamber B, Komuniecki RW (2009) Three distinct amine receptors operating at different levels within the locomotory circuit are each essential for the serotonergic modulation of chemosensation in C. elegans. J Neurosci 29:1446-1456.

Hart AC, Kass J, Shapiro JE, Kaplan JM (1999) Distinct signaling pathways mediate touch and osmosensory responses in a polymodal sensory neuron. J Neurosci 19:1952-1958.

Hills T, Brockie PJ, Maricq AV (2004) Dopamine and glutamate control area-restricted search behavior in. Caenorhabditis elegans. J Neurosci 24:1217-1225.

Jose AM, Smith JJ, Hunter CP (2009) Export of RNA silencing from C. elegans tissues does not require the RNA channel SID-1. Proc Natl Acad Sci U S A 106:2283-2288.

Kimple RJ, Kimple ME, Betts L, Sondek J, Siderovski DP (2002) Structural determinants for GoLoco-induced inhibition of nucleotide release by $\mathrm{G} \alpha$ subunits. Nature 416:878-881.

Kopein D, Katanaev VL (2009) Drosophila GoLoco-protein Pins is a target of $\mathrm{G} \alpha_{\mathrm{o}}$-mediated $\mathrm{G}$ protein signaling. Mol Biol Cell 20:3865-3877.

Mendel JE, Korswagen HC, Liu KS, Hajdu-Cronin YM, Simon MI, Plasterk RH, Sternberg PW (1995) Participation of the protein $\mathrm{G} \alpha_{\mathrm{o}}$ in multiple aspects of behavior in C. elegans. Science 267:1652-1655.

Miller KG, Rand JB (2000) A role for RIC-8 (Synembryn) and GOA-1
(G(o)alpha) in regulating a subset of centrosome movements during early embryogenesis in Caenorhabditis elegans. Genetics 156:1649-1660.

Mochizuki N, Cho G, Wen B, Insel PA (1996) Identification and cDNA cloning of a novel human mosaic protein, LGN, based on interaction with G alpha i2. Gene 181:39-43.

Natochin M, Lester B, Peterson YK, Bernard ML, Lanier SM, Artemyev NO (2000) AGS3 inhibits GDP dissociation from galpha subunits of the Gi family and rhodopsin-dependent activation of transducin. J Biol Chem 275:40981-40985.

Nipper RW, Siller KH, Smith NR, Doe CQ, Prehoda KE (2007) G $\alpha_{\mathrm{i}}$ generates multiple Pins activations states to link cortical polarity and spindle orientation in Drosophila neuroblasts. Proc Natl Acad Sci U S A 104:14306-14311.

Pandit R, de Jong JW, Vanderschuren LJ, Adan RA (2011) Neurobiology of overeating and obesity: The role of melanocortins and beyond. Eur J Pharmacol 660:28-42.

Patikoglou GA, Koelle MR (2002) An N-terminal region of Caenorhabditis elegans RGS proteins EGL-10 and EAT- 16 directs inhibition of $\mathrm{G} \alpha_{\mathrm{o}}$ versus $\mathrm{G} \alpha$ s signaling. J Biol Chem 277:47004-47013.

Porter MY, Koelle MR (2010) RSBP-1 is a membrane-targeting subunit required by the Galpha(q)-specific but not the Galpha(o)-specific R7 regulator of $\mathrm{G}$ protein signaling in Caenorhabditis elegans. Mol Biol Cell 21:232-243.

Sanada K, Tsai LH (2005) G protein $\beta \gamma$ subunits and AGS3 control spindle orientation and asymmetric cell fate of cerbral cortical progenitors. Cell 122:119-131.

Schaefer M, Shevchenko A, Shevchenko A, Knoblich JA (2000) A protein complex containing Inscuteable and the $\mathrm{G} \alpha$-binding protein Pins orients asymmetric cell divisions in Drosophila. Curr Biol 10:353-362.

Ségalat L, Elkes DA, Kaplan JM (1995) Modulation of serotonin-controlled behaviors by $\mathrm{G} \alpha_{\mathrm{o}}$ in Caenorhabditis elegans. Science 267:1648-1651.

Srinivasan DG, Fisk RM, Xu H, van den Heuvel S (2003) A complex of LIN-5 and GPR proteins regulates G protein signaling and spindle function in C. elegans. Genes Dev. 17:1225-1239.

Takesono A, Cismowski MJ, Ribas C, Bernard M, Chung P, Hazard S 3rd, Duzic E, Lanier SM (1999) Receptor-independent activators of heterotrimeric G-protein signaling pathways. J Biol Chem 274:33202-33205.

Tall GG, Gilman AG (2005) Resistance to inhibitors of cholinesterase 8A catalyzes relase of $\mathrm{G} \alpha_{\mathrm{i}}$-GTP and nuclear mitotic apparatus protein (NuMA) form NuMA/LGN/G $\alpha_{\mathrm{i}}$-GDP complexes. Proc Natl Acad Sci U S A 102:16584-16589.

Tall GG, Krumins AM, Gilman AG (2003) Mammalian Ric-8A (synembryn) is a heterotrimeric Galpha protein guanine nucleotide exchange factor. J Biol Chem 278:8356-8362.

Tanis JE, Moresco JJ, Lindquist RA, Koelle MR (2008) Regulation of serotonin biosynthesis by the $\mathrm{G}$ proteins Galphao and Galphaq controls serotonin signaling in. Caenorhabditis elegans. Genetics 178:157-169.

Thomas CJ, Tall GG, Adhikari A, Sprang SR (2008) Ric-8A catalyzes guanine nucleotide exchange on $\mathrm{G}$ alphail bound to the GPR/GoLoco exchange inhibitor AGS3. J Biol Chem 283:23150-23160.

Vucetic Z, Reyes TM (2010) Central dopaminergic circuitry controlling food intake and reward: implications for the regulation of obesity. Wiley Interdiscip Rev Syst Biol Med 2:577-593.

Wang H, Ng KH, Qian H, Siderovski DP, Chia W, Yu F (2005) Ric-8 controls Drosophila neural progenitor asymmetric division by regulating heterotrimeric G proteins. Nat Cell Biol 7:1091-1098.

Willard FS, Zheng Z, Guo J, Digby GJ, Kimple AJ, Conley JM, Johnston CA, Bosch D, Willard MD, Watts VJ, Lambert NA, Ikeda SR, Du Q, Siderovski DP (2008) A point mutation to Galphai selectively blocks GoLoco motif binding: direct evidence for Galpha-GoLoco complexes in mitotic spindle dynamics. J Biol Chem 283:36698-36710.

Wragg RT, Hapiak V, Miller SB, Harris GP, Gray J, Komuniecki PR, Komuniecki RW (2007) Tyramine and octopamine independently inhibit serotonin-stimulated aversive behaviors in $C$ elegans through two novel amine receptors. J Neurosci 27:13402-13412.

Yu F, Morin X, Cai Y, Yang X, Chia W (2000) Analysis of partner of inscuteable, a novel player of Drosophila asymmetric divisions, reveals two distinct steps in inscuteable apical localization. Cell 100:399-409. 